MAIA, Tatyana de Amaral; ALVES, Luís Alberto Marques; HERMETO, Miriam; RIBEIRO, Cláudia Sofia Pinto (Org.). (Re)Construindo o passado: o papel insubstituível do ensino da História. Porto Alegre: EdiPUCRS; Porto: CITCEM, 2016. 286 p.

\title{
A RESPONSABILIDADE SOCIAL DO ENSINO DE HISTÓRIA
}

Maria Andréa Angelotti Carmo ${ }^{1}$

Historicamente, uma das grandes preocupações das classes, dos grupos, dos indivíduos que dominaram e dominam as sociedades está no controle sobre a memória, o esquecimento e os silêncios na História, conforme argumenta Le Goff (2003). Nessa perspectiva, as batalhas entre os registros e a hegemonia sobre determinada memória são marcadas pelos silêncios, esquecimentos e confrontos que compõem a história das sociedades humanas e, em especial, das democracias atuais. As sociedades, cujas histórias encontram-se inseridas em processos ditatoriais, têm enfrentado seus passados recentes a partir de temas e conteúdos compreendidos como sensíveis, dolorosos e de difícil consenso.

É o caso das sociedades ibéricas e sul-americanas. Qual, então, o papel do ensino de História no processo de construção, reelaboração, manutenção, mediação, e outros tratamentos da memória, nessas sociedades? Um olhar atento sobre esses passados, e seu ensino, nas sociedades ibéricas e sulamericanas, constitui a feliz contribuição que se apresenta na coletânea (Re)Construindo o Passado: o papel insubstituível do ensino de História, publicada pela Editora da Pontifícia Universidade do Rio Grande do Sul em parceria com o Centro de Investigação Transdisciplinar Cultura, Espaço e Memória (CITCEM) da Universidade do Porto, Portugal.

1 Professora Adjunta no Instituto de História da Universidade Federal de Uberlândia. Doutora em História Social pela Pontifícia Universidade Católica de São Paulo. Pós-doutoranda em História pela Universidade do Porto, Portugal. 
A obra é organizada pelas professoras brasileiras Tatyana de Amaral Maia, da Pontifícia Universidade Católica do Rio Grande do Sul (PUC-RS), Miriam Hermeto, da Universidade Federal de Minas Gerais (UFMG), e pelos professores portugueses Luís Alberto Marques Alves e Cláudia Sofia Pinto Ribeiro, ambos da Universidade do Porto. A coletânea conta com análises e pesquisas da temática no Brasil e em Portugal e traz, ainda, a participação de pesquisadores espanhóis e argentinos num exercício em que compreendem a necessidade contínua de reflexão sobre os usos do passado, e de como eles se apresentam, e são tratados, no ensino. Os artigos resultam de distintas pesquisas que envolvem perspectivas de alunos, professores, propostas curriculares e manuais didáticos de ensino de História. Ainda, abordam a forma como memórias, narrativas, percepções do passado são eleitas para comporem, ou não, o quadro dos conteúdos, formas de apresentação e abordagens históricas.

A coletânea está dividida em duas partes, de modo a contemplar os estudos sobre as sociedades ibéricas e sul-americanas em suas peculiaridades e particularidades: Os passados dolorosos na Europa e Os passados dolorosos na América Latina são compostas por quatro artigos cada uma, o que disponibiliza, ao leitor, um amplo panorama da temática nos diferentes países e contextos, a partir de análises de um rico e diverso leque de fontes e do emprego das mais diversas metodologias.

Na primeira parte, Luís Alberto Alves e Cláudia Ribeiro refletem sobre o que temos feito dos "nossos passados históricos", dos quais não queremos lembrar. Ensinar passados dolorosos, aprender com o uso pedagógico da história apresenta os resultados e análises de uma longa pesquisa realizada com estudantes do $9^{\circ}$. e do $12^{\circ}$. anos da Educação Básica, e professores de História, em Portugal. Os autores compreendem que o passado, por mais doloroso que seja, deve transformar-se "num conhecimento inteligível e, a partir daí, acreditar num devir de melhoria (esperança) que seja suportado na inteligibilidade" ( $p$. 28). Os passados dolorosos precisariam ser trabalhados por docentes "preparados cientificamente e intelectualmente honestos", a fim de fornecer "recursos variados, perspectivas heterogêneas, sínteses consensuais englobando contributos dos seus interlocutores" (p. 27). Por meio das análises de entrevistas com professores e alunos, os autores tratam as "questões socialmente vivas" e 
remanescentes da Guerra Colonial, consideradas, pela maioria dos entrevistados, como o ápice do passado doloroso da sociedade portuguesa.

$\mathrm{Na}$ análise de Aprendizagem histórica dos passados dolorosos: as "guerras coloniais" nas narrativas de jovens portugueses, Marçal de Menezes Paredes e Tatyana de Amaral Maia refletem acerca da aprendizagem e educação histórica como campo de pesquisa em que se busca "investigar os processos pelos quais alunos constroem o seu conhecimento histórico e como aprendem os conceitos estruturantes da disciplina" (p. 51). Em um segundo momento, os autores analisam as maneiras de compreender a história da Guerra Colonial dos alunos portugueses, considerando os passados dolorosos circunscritos às experiências traumáticas e "passados que ameaçaram romper com a cultura histórica moderna que inclui a defesa de valores considerados universais e intrínsecos aos indivíduos" (p. 63). Nessa pesquisa, a apreciação das narrativas de estudantes leva os autores a entenderem que a História ensinada ainda exerce um papel tido por essencial na compreensão da experiência vivida. No entanto, revelam, também, os desejos de esquecimento, o silêncio sobre esse passado ou mesmo o tratamento superficial das questões na forma como são abordadas no ensino ou pela opinião pública.

Beatriz de Las Heras, no artigo (Re)construindo a história a partir da (re)presentação visual: memória da Guerra Civil espanhola em Madrid por meio da fotografia, argumenta que a fotografia não mostra a realidade, mas mostra realidades ( $p$. 82). A autora trabalha quatro conceitos chaves considerados relevantes para a compreensão do processo de (re)construção da história a partir das imagens: memória, fragmento, saber lateral e (re)presentação.

As formas como trabalharam os fotógrafos na cidade de Madrid, bem como as estratégias de propaganda mais utilizadas durante a guerra, também são consideradas ao longo do texto. Apresentando um conjunto de fotografias e tecendo profundas análises, Las Heras aponta as estratégias de mostrar, ocultar, reter e reconduzir, utilizadas pelas autoridades durante a guerra civil espanhola. Neste texto, a fotografia e todo seu processo de "fabricação" são compreendidos como um processo de criação de um discurso que finda por se converter na memória do acontecimento. A leitura nos apresenta a inquietação e preocupação quanto aos usos, produção e emprego das imagens, especialmente na sociedade 
contemporânea, em que a chegada da tecnologia se converteu em um grande programador de olhares, e registros, de memórias.

No artigo Abordagem ao ensino da Guerra Civil e da ditadura de Franco na Espanha contemporânea, Claire Magill observa as "diferenças nas abordagens dos professores no que respeita à relação explícita entre o passado e o presente" (p. 116), e analisa as metodologias adotadas pelos profissionais do ensino ao ministrarem os temas da Guerra Civil e da Ditadura de Franco. As investigações da autora levam-na a deparar-se com cinco grupos/categorias de professores, assim descritos: aqueles que não se privaram de ensinar o tema potencialmente polêmico, mas também não criaram oportunidades para abordar tais questões (p. 120); aqueles que enfrentam verdades desconfortáveis, mitos e preconceitos, e procuram sensibilizar seus alunos para os perigos de reduzir questões históricas e complexas a explicações simplistas e maniqueístas da História ( $p$. 122); aqueles que em vez de apresentar múltiplas perspectivas e incentivar seus alunos a fazerem suas próprias escolhas, tendem a apresentar suas próprias opiniões, sem incentivar o debate ou a discussão (p. 126); aqueles que mostram clara preferência por manterem-se afastados de questões polêmicas ou controversas; aqueles que relutam em abordar o tema ou relacionar o passado e o presente; aqueles que tratam a questão, mas não conseguem explorar o tema em profundidade.

Não se trata apenas de nomear uma ou outra atuação docente, tampouco culpar os docentes e sua atuação, mas busca-se refletir acerca das dificuldades encontradas para trabalhar questões não amplamente consensuais e conflituosas na sociedade contemporânea. Ressalta-se a necessidade de desenvolver programas de formação profissional, adequados e pertinentes, no contexto espanhol e em outros contextos.

$\mathrm{Na}$ segunda parte da obra temos $O$ ensino de história e os "passados dolorosos": a questão das ditaduras na América Latina, texto no qual Marcos Napolitano e Mariana Villaça apresentam o debate historiográfico sobre a temática, propondo oferecer alguns subsídios para que o professor possa abordar o tema, instigando os alunos a compreendê-lo historicamente (p. 155). Após apresentar um panorama das ditaduras na América Latina e suas principais questões, os autores indicam um conjunto de temas, conteúdos, materiais, e 
atividades didáticas, que podem auxiliar os professores no tratamento dessas questões, além de indicarem bibliografias sobre os golpes e regimes militares.

Por sua vez, Maria Paula Gonzáles debruça-se sobre a última ditadura na Argentina e a observa como "um passado que não passa" perpetua-se em um grande desafio para a escola habituada e convencida de seu caráter neutro. 0 Ensino da História e passados sensíveis: olhares sobre o caso argentino provocanos ao trazer uma abordagem acerca das narrativas, dos regulamentos educativos e, principalmente, das práticas e desafios que se apresentam aos professores de história no ensino de uma temática histórica do tempo presente. Após mergulhar na documentação, e analisar as práticas de ensino como estratégias e táticas construídas no tempo e no contexto, a autora aponta que o tratamento da história nas escolas está "tensionado pela natureza recente e polêmica, a condição aberta e inacabada, o caráter traumático, as questões éticas e políticas, o privilégio da memória sobre a história" (p. 219). A autora destaca, ainda, a relevância de se reconhecer os problemas acarretados pelo tratamento dado ao passado, oportuniza a revisão das maneiras pelas quais pensamos a história como reelaboração do passado, e os significados que damos ao seu ensino.

Com o título de Justa memória, dívida ética e passados-presentes dolorosos: questões a partir da análise de interpretações sobre a ditadura militar brasileira (1964-1985) em livros didáticos de História, o penúltimo artigo da obra apresenta a reflexão de Mateus Henrique de Faria Pereira e Miriam Hermeto, que versa sobre a "tensão entre as práticas do dever de memória e do trabalho de memória" (p. 228). Os autores discorrem sobre os temas da arte engajada e do Golpe de 1964, e de como eles são abordados e dispostos nos 46 manuais didáticos analisados. Os livros didáticos são compreendidos como produtos culturais e instrumentos pedagógicos que se tornaram guardiões e construtores da memória e do saber escolar (p. 243), e o ensino de história pode contribuir para o exercício de superação de uma história "puramente traumática" em direção à transformações no e do presente. O texto encoraja a discussão de maneira crítica e sistemática da escrita da produção didática e a reflexão sobre o dever e o trabalho de memória, cuja incumbência parece incidir sobre ensino de 
História, de modo a contribuir para que processos históricos não voltem a ocorrer.

O empenho contido no último artigo da obra, Os passados dolorosos no ensino de História: trauma, memória e direitos humanos, de Tatyana de Amaral Maia, é compreender como a legislação e os documentos curriculares que orientam o ensino de História tratam do tema e expõem a ação oblíqua do Estado brasileiro, quanto ao dever de memória e à ampliação da justiça de transição (p. 264). Após profundas análises acerca da instituição e atuação da Comissão Nacional da Verdade e seus contextos, bem como dos Parâmetros Curriculares Nacionais, a autora provoca quanto à naturalização da seleção de determinados conteúdos históricos, e sobre o discurso meramente retórico de defesa dos direitos humanos, apontando que é preciso integrar os currículos dedicados ao ensino de História e à Educação em Direitos Humanos, de modo a favorecer a superação dos legados autoritários na sociedade. Para a autora, o ensino de História pode ser um espaço privilegiado para a reflexão sobre a ditadura militar e seus legados, e pode romper com a "política do esquecimento" que teria sido implantada junto com a "transição negociada" experimentada pela sociedade brasileira (p. 263).

A obra (Re)Construindo o passado: o papel insubstituível do ensino da História instaura a oportunidade de olhar para os passados dolorosos sob a perspectiva do ensino, mas também possibilita ampliar o olhar para além de materiais didáticos e conteúdos curriculares, apresentando diferentes fontes, linguagens, e contextos, em que se pesam elementos como o compromisso e a honestidade intelectual para com a sociedade e seus enfrentamentos sociais e históricos, bem como para com as populações, e grupos, diretamente marcados pela violência, cujas memórias parecem manter-se sob a "sombra" dos registros e discursos hegemônicos.

A coletânea oportuniza rememorar o privilégio e o dever do ensino de História no processo de (re)construção de passados recentes, reconhecimentos e esclarecimentos de usos e abusos. (Re)construção de sua força no combate aos "esquecimentos" e de sua possibilidade de contribuição na formação de uma sociedade nas quais suas histórias não repitam os processos cingidos pela dor. 
Recebido em 18 de setembro de 2017 Aprovado em 30 de dezembro de 2017 